\title{
Early-stage (cT2N0) esophageal cancer: Should induction therapy be a standard?
}

\author{
Michael Lanuti, MD
}

\author{
From the Division of Thoracic Surgery, Massachusetts General Hospital, Boston, Mass. \\ Disclosures: Author has nothing to disclose with regard to commercial support. \\ Received for publication Feb 4, 2018; accepted for publication Feb 11, 2018; available ahead of print March 7 , \\ 2018. \\ Address for reprints: Michael Lanuti, MD, 55 Fruit St, Founders 7, Boston, MA 02114 (E-mail: mlanuti@mgh. \\ harvard.edu). \\ J Thorac Cardiovasc Surg 2018;155:2231-2 \\ $0022-5223 / \$ 36.00$ \\ Copyright (C) 2018 by The American Association for Thoracic Surgery \\ https://doi.org/10.1016/j.jtcvs.2018.02.029
}

In this issue of the Journal, Semenkovich and colleagues ${ }^{1}$ develop a decision analysis to determine the optimal therapy for patients with clinical T2N0 esophageal cancer: upfront esophagectomy $+/-$ adjuvant therapy versus induction chemoradiation followed by surgery. This is an important question in thoracic oncology that has yet to be answered. The consistent inaccuracy of endoscopic ultrasonography staging of T2N0 disease shapes the fragile underpinning on which therapeutic recommendations are derived. The concordance of pathologic T2N0 disease with clinical T2N0 is $<30 \%$ in published series, ${ }^{2}$ where most patients are upstaged.

The authors subsequently analyzed 1520 patients with T2N0 from the National Cancer Database who underwent upfront surgery from 1998 to 2012. The overall model yielded a survival of 48.3 months in those undergoing upfront surgery and 45.9 months in those undergoing induction therapy. When varying the likelihood of upstaging, if the probability of upstaging was $>48.1 \%$, induction therapy conferred a survival benefit over upfront surgery. The authors conclude that the routine application of induction therapy in all patients with cT2N0 was likely to be harmful rather than beneficial with regard to survival. The real challenge remains the detection of microscopic nodal disease in T1-2 esophageal cancer, where computed tomography, endoscopic ultrasonography, and/or positron emission tomography still fall short.

Although this decision analysis can theoretically improve the selection of patients with cT2N0 for induction therapy, its implementation may have some challenges. The authors identified 3 high-risk variables to predict upstaging in cT2N0 disease: tumor size $>3 \mathrm{~cm}$, tumor grade (3-4), and the presence of lymphovascular invasion. The histologic variables of tumor grade and lymphovascular invasion are not always apparent in preoperative biopsies, thus weakening the application of the decision model. The National Cancer Database patient population used in this analysis did not include many patients treated with the neoadjuvant chemoradiotherapy

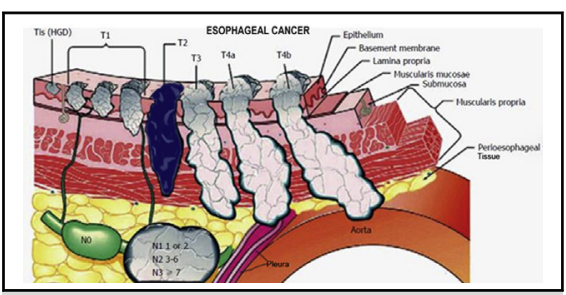

T2 disease, elusive on diagnostic imaging.

\section{Central Message}

Induction therapy for cT2N0 esophageal cancer should always be considered except in carefully selected patients with a low risk of pathologic upstaging, in whom upfront esophagectomy may be appropriate.

See Article page 2221 .

regimen described in the ChemoRadiotherapy for Oesophageal Cancer Followed by Surgery Study (CROSS) trial (used to construct some parameters in this decision analysis), which was not widely adopted until after $2012 .{ }^{3}$ Since the CROSS regimen has been well tolerated in patients with locally advanced esophageal cancer, the threshold to implement such a strategy in earlier stage disease (cT2N0) has been lowered. Given the high frequency of upstaging in patients harboring cT2N0, it is not clear how this decision analysis will alter an otherwiseaggressive multimodality approach (including an induction strategy) in patients with good performance or younger age. Moreover, one of the downsides of adjuvant chemotherapy and/or radiation after upfront esophagectomy for cT2N0 disease is that the treatments are often not well tolerated just after surgery, particularly concurrently, and the field of radiation becomes larger (original tumor bed extending to the esophagogastric anastomosis).

Despite some shortcomings, the authors should be congratulated since this decision analysis addresses a therapeutic dilemma in thoracic surgery that will further refine the selection of true early-stage T2 disease and appropriately apply an induction strategy to the greater-risk cT2N0 patients.

\section{References}

1. Semenkovich TR, Panni RZ, Hudson JL, Thomas T, Elmore LC, Chang S-H, et al. Comparative effectiveness of upfront esophagectomy versus induction chemoradiation in clinical stage T2N0 esophageal cancer: a decision analysis. $J$ Thorac Cardiovasc Surg. 2018;155:2221-30.e1. 
2. Crabtree TD, Kosinski AS, Puri V, Burfeind W, Bharat A, Patterson GA, et al. Evaluation of the reliability of clinical staging of T2 N0 esophageal cancer: a review of the Society of Thoracic Surgeons database. Ann Thorac Surg. 2013;96:382-90.
3. van Hagen P, Hulshof MC, van Lanschot JJ, Steyerberg EW, van Berge Henegouwen MI, Wijnhoven BP, et al. Preoperative chemoradiotherapy for esophageal or junctional cancer. N Engl J Med. 2012;366:2074-84. 